\title{
What process attributes of clinical genetics services could maximise patient benefits?
}

\author{
Marion McAllister*, ${ }^{\text {1,2 }}$, Katherine Payne ${ }^{1,3}$, Rhona MacLeod ${ }^{2}$, Stuart Nicholls ${ }^{1}$, \\ Dian Donnai $^{1,2}$ and Linda Davies ${ }^{1,3}$
}

\begin{abstract}
${ }^{1}$ The Nowgen Centre for Genetics in Healthcare, Manchester, $U K ;{ }^{2}$ Medical Genetics Research Group, The University of Manchester, St Mary's Hospital, Manchester, UK; ${ }^{3}$ Health Economics Research at Manchester, School of Communitybased Medicine, The University of Manchester, Manchester, UK
\end{abstract}

There is limited evidence about what process attributes of clinical genetics services may be highly valued by patients and service providers. The aim in this qualitative grounded theory study was to explore what process attributes may be highly valued by those stakeholders. Seven focus groups $(n=33)$ and nineteen one-to-one interviews were conducted (total sample size $=52$ ). Five process attributes were identified as highly valued by patients and health professionals: (1) local and accessible services (2) open access and follow-up, (3) coordinated, tailored family care, (4) quality of the patient-clinician relationship and (5) time to talk. These findings will be useful in designing models of service delivery that could be tested in intervention studies.

European Journal of Human Genetics (2008) 16, 1467-1476; doi:10.1038/ejhg.2008.121; published online 2 July 2008

Keywords: process; patient benefits; clinical genetics services; qualitative research

\section{Introduction}

It has been argued that more research is needed for investigating the process of genetic counselling. ${ }^{1}$ Different perspectives may be taken on the meaning of 'process'. 'Process' has been defined, by health economists, as 'anything in the individual's utility function (strategy for goal attainment) other than the final health outcome that the intervention affects'. ${ }^{2}$ Process, defined in this way, can include attributes such as access to the intervention ${ }^{2}$ and can have a significant impact on patient well-being. Process and outcome may be linked, particularly where outcome measures used are subjective, rather than objective, although this is contested. ${ }^{3-5}$ However, clinical genetics services have developed with little agreement about the best way to measure process and outcomes. ${ }^{6,7}$

*Correspondence: Dr M McAllister, The Nowgen Centre for Genetics in Healthcare, The University of Manchester, The Nowgen Centre, 29 Grafton Street, Manchester M13 9WU, UK. Tel: +44 161276 8979; Fax + 44161276 4058; E-mail: marion.mcallister@manchester.ac.uk Received 21 December 2007; revised 14 May 2008; accepted 5 June 2008; published online 2 July 2008
There are few data on models of service delivery ${ }^{8}$ and, until recently, there have been few randomised controlled trials (RCTs) in the clinical genetics arena. One UK randomised trial ${ }^{9}$ found no differences in psychological outcomes (anxiety, cancer worry, perceived risk, interest in genetic testing and satisfaction) when comparing a multidisciplinary specialist genetics service with surgical provision for women at familial risk for breast cancer. Although this study described the health professionals involved in providing the two services, and some details about the interventions offered, the process attributes of the services compared, such as waiting times, proximity, length of consultation and so on were not clear. One US RCT ${ }^{10}$ compared decision-making about BRCA1 testing in women with a family history of breast cancer using (1) an education-only approach and (2) an education plus counselling approach with (3) waiting list controls. Interventions (1) and (2) led to significant increases in knowledge; only intervention (2) significantly increased perceptions of the limitations and risks of BRCA1 testing and decreases in the perceived benefits. Again, although 
this study was clear about the interventions offered in the three arms of the trial, and described aspects of the process of care in the three arms, the value of these process attributes were not measured.

Another recent $\mathrm{RCT}^{11}$ of familial breast cancer genetic counselling compared preclinic telephone contact followed by a consultation with a junior doctor with two clinic consultations with a nurse counsellor supervised by a consultant geneticist. No significant differences in patient outcomes were detected using measures of risk perception, understanding of breast cancer risk factors, anxiety and satisfaction. It is clear from an examination of these three studies, that first, there is no agreement about the theoretical underpinnings to the design of interventions aimed at improving patient outcomes in clinical genetic services; second, there appears to be no agreement about appropriate outcome measures, and finally, that the value of process attributes are not being measured.

Studies in other areas of healthcare, for example management of abnormal Pap smears ${ }^{2}$ and provision of in vitro fertilisation services, ${ }^{12}$ provide evidence that the process of clinical care can determine the value of interventions to patients, and that patients may make trade-offs between process and outcome attributes. For example, preferring to attend a specialist hospital, even if it means travelling further. In the context of clinical genetics, one quantitative study ${ }^{13}$ focusing on the client/counsellor encounter, found no significant correlations between process and outcome attributes. However, the authors acknowledged that this may have been due to (1) use of irrelevant or inadequate measures of process or outcome or (2) using correlations and linear regressions inappropriately. The assumption underlying the use of correlations and linear regressions to study interaction is that 'more of a good thing', in this case, type of utterances, will lead to better outcomes. Stiles ${ }^{3,14,15}$ suggested that this assumption may be flawed if counsellors are effectively tailoring communication to the individual needs of the patient; that is, the process components will co-vary with patient requirements but not outcomes. There is evidence that patients do benefit from aspects of the process of care in clinical genetics, such as time spent with the clinician, ${ }^{16}$ how information is provided, ${ }^{16}$ a positive, empathic relationship, ${ }^{16-19}$ and 'being seen by an expert' perceived as 'adopting' the problem on the patient's behalf. ${ }^{20}$

In summary, there is some evidence about what process attributes of clinical genetics services may be highly valued by patients and service providers. This paper reports findings from a qualitative study identifying attributes of the process of care in clinical genetics services that are valued by patients, patient group representatives and service providers. This study forms part of a broader qualitative study, designed to explore the perspectives of those stakeholders on delivery, benefits and harms of clinical genetics services. Previous papers reporting the results of this study have described findings relating to the effects of genetic diseases on individuals and families ${ }^{21,22}$ and summarising the possible outcomes of care from using clinical genetics services. ${ }^{23}$ The findings reported here will be useful in designing models of service delivery that could (a) be tested in intervention studies, and (b) potentially maximise patient benefits.

\section{Methodology}

This qualitative study forms part of a larger research programme aimed at developing outcome measures ${ }^{7,21-24}$ for clinical genetics services. This study specifically aimed to:

1. Explore what attributes of the care process (i) are valued by participants and (ii) may be important determinants of the patient benefits.

2. Explore the conceptual relationship between these process attributes and empowerment, a concept summarising the valued outcomes of using clinical genetics services. $^{23}$

Qualitative methods were used because there is little evidence about how clinical genetics services can best be provided to maximise patient benefits. Qualitative methods are appropriate for research areas that are not well-understood, where the relevant variables have not yet been fully identified and where exploring people's views is important. ${ }^{25}$ Grounded theory is an inductive qualitative research method where the aim is to develop a model or set of hypotheses about the conceptual relationships in the research area, ${ }^{26-28}$ and was the approach followed in this research. The aims were to identify the range of process attributes that can influence patient outcomes and elucidate the conceptual relationships between them, rather than identify prevalence of themes in the data, or identify which process attributes were most important.

This study employed a combination of focus groups ${ }^{21}$ and interviews. ${ }^{22,23}$ Seven focus groups were conducted with patients of clinical genetics services, their representatives from patient support organisations, and genetics health professionals in the UK. The focus group/interview schedule has been published elsewhere. ${ }^{21}$ The key question for the results reported here was 'What aspects of genetics services are effective in achieving good patient outcomes?', ${ }^{21}$ and further exploration of responses to this question. To privilege patient views, focus groups were supplemented by 19 one-to-one interviews with another set of patients and patient group representatives, ${ }^{22,23}$ representing a broader range of genetic conditions (see Table 1), to obtain a critical assessment of themes identified in the focus groups and to check for data saturation. The final data analysis used the combined data from interviews and focus groups.

Local Research Ethics Committee approval was obtained prior to recruitment. Recruitment procedures are presented 
Table 1 Participation in focus groups and interviews

\begin{tabular}{|c|c|c|c|c|c|c|c|}
\hline & \multirow[b]{2}{*}{ Focus groups (n) (\%) } & \multirow[b]{2}{*}{ Interviews (n) (\%) } & \multicolumn{2}{|c|}{ Patient group representatives } & \multirow{2}{*}{$\begin{array}{c}\text { Genetics } \\
\text { clinicians } \\
\text { Total } \\
\text { (n) (\%) }\end{array}$} & \multirow{2}{*}{$\begin{array}{c}\text { Referring } \\
\text { clinicians } \\
\text { Total } \\
\text { (n) (\%) }\end{array}$} & \multirow{2}{*}{$\begin{array}{c}\text { Total } \\
\text { (n) }(\%)\end{array}$} \\
\hline & & & Focus groups (n) (\%) & Interviews (n) (\%) & & & \\
\hline $\begin{array}{l}\text { Number } \\
\text { approached }\end{array}$ & 107 & 35 & 24 & 24 & 17 & 52 & 259 \\
\hline No response & $60(56 \%)$ & $17(49 \%)$ & $5(21 \%)$ & $12(50 \%)$ & $0(0 \%)$ & $18(35 \%)$ & $112(43 \%)$ \\
\hline Declined & $25(23 \%)$ & $9(26 \%)$ & $8(33 \%)$ & $2(8 \%)$ & $1(6 \%)$ & $25(48 \%)$ & $70(27 \%)$ \\
\hline $\begin{array}{l}\text { Agreed to } \\
\text { participate }\end{array}$ & $22(21 \%)$ & $9(26 \%)$ & $11(46 \%)$ & $10(42 \%)$ & $16(94 \%)$ & $9(17 \%)$ & $77(30 \%)$ \\
\hline $\begin{array}{l}\text { Unable to } \\
\text { participate }\end{array}$ & $12(11 \%)$ & $0(0 \%)$ & $2(8 \%)$ & $0(0 \%)$ & $7(41 \%)$ & $4(8 \%)$ & $25(10 \%)$ \\
\hline Participated & $\begin{array}{c}10(9 \%) \\
\text { Conditions represented: } \\
\text { BRCA1/2 } \\
\text { Family history of colon } \\
\text { cancer } \\
\text { Gorlin syndrome } \\
\text { Neurofibromatosis } 2 \\
\text { Adult polycystic kidney } \\
\text { disease }\end{array}$ & $\begin{array}{c}9(26 \%) \\
\text { Conditions represented: } \\
\text { Marfan syndrome } \\
\text { Chromosome translocations } \\
\text { Duchenne muscular dystrophy } \\
\text { Fragile } X \text { syndrome } \\
\text { Huntingtons Disease } \\
\text { Leber's hereditary optic atrophy } \\
\text { Multiple endocrine neoplasia } \\
\text { Spinocerebellar ataxia }\end{array}$ & $\begin{array}{c}9(38 \%) \\
\text { Conditions represented: } \\
\text { Huntingtons Disease } \\
\text { Hereditary breast cancer } \\
\text { Gorlin syndrome } \\
\text { Motor Neurone Disease } \\
\text { Von Hippel Lindau Disease } \\
\text { Myotonic dystrophy }\end{array}$ & $\begin{array}{c}10(42 \%) \\
\text { Conditions represented: } \\
\text { Costello syndrome } \\
\text { Hereditary multiple exostoses } \\
\text { Lower limb conditions } \\
\text { Mitochondrial diseases } \\
\text { Multiple endocrine neoplasia } \\
\text { Skeletal dsyplasias } \\
\text { Retinitis pigmentosa } \\
\text { Rubinstein-Taybi syndrome } \\
\text { Sudden adult death syndrome }\end{array}$ & $9(53 \%)$ & $5(10 \%)$ & $52(20 \%)$ \\
\hline $\begin{array}{l}\text { Participation } \\
\text { by group }\end{array}$ & & $19(13 \%)$ & & $(40 \%)$ & $9(53 \%)$ & $5(10 \%)$ & $52(20 \%)$ \\
\hline
\end{tabular}
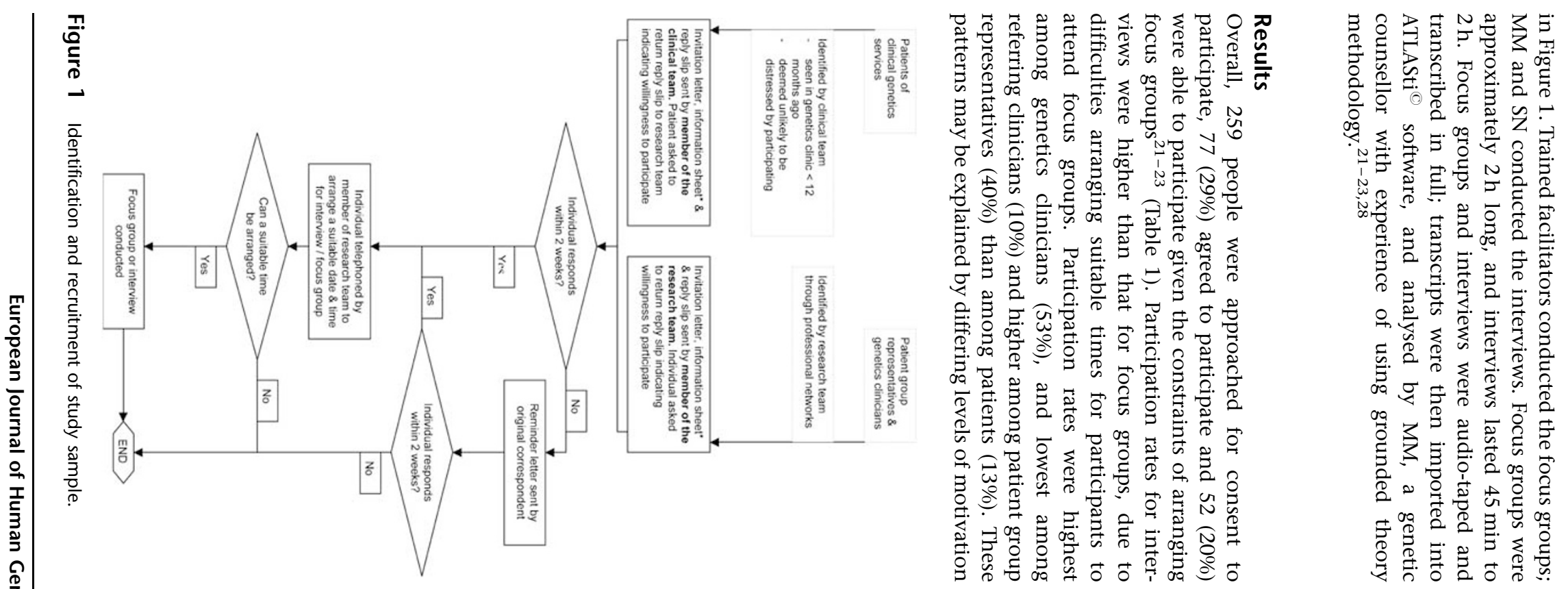
among the different participating groups. The groups were all self-selected (see Figure 1), introducing some bias, but this was necessary due to the requirements of the research ethics committee.

Five distinct process attributes were identified in the focus groups that may contribute to good patient outcomes in clinical genetics services: (1) local and accessible services (2) open access and yearly follow-up (3) coordinated, tailored family care (4) quality of the relationship and (5) time to talk. The interviews confirmed the themes that emerged from the focus groups, and added further depth to the analysis. There were no contradictions between the themes identified in the focus groups and those identified in the interviews.

\section{Local and accessible services}

By their nature, genetic conditions affect multiple family members. There can be a significant financial and time burden upon families to attend regional genetics services and other specialist services for appointments. Many families need to travel long distance for appointments. Peripheral clinics in local areas are highly valued by service users and user representatives.

I had three family, four family members affected and actually to manage that knowing that all the specialist services are generally in (city) and I live in (town 60 miles from city), you know [...\} it has huge financial implications [...] I think it's good that genetics, or the staff that are involved actually come out to the local hospitals. (patient group representative, FG2, family history of Gorlin syndrome)

Service providers acknowledge that although providing services locally does cut down on patient non-attendance, provision of more local services are patchy and incomplete, are not incorporated into government targets, and interest in setting up local services varies.

I think geography is a difficulty that we are aware of, [...] there aren't perhaps enough peripheral clinics and people have to wait longer to be seen in some places. (Genetic counsellor, FG4)

Clinicians referring to clinical genetics from primary as well as secondary care felt that genetic counselling was best provided at tertiary level because patients are more likely to accept information provided by a specialist. This is also influenced by consumer culture and people demanding to see specialists but is contrary to current moves in the British National Health Service (NHS) to devolve as much as possible to primary care.

If (genetic counselling) was done in one of our surgeries the patient experience would be very different. By going to tertiary centre [...] they have seen someone who they feel knows more, and are more willing perhaps to accept their opinion. And you can influence their decisions a lot lot better rather than it being somewhere else where they don't actually feel they've had that special treatment. (General Practitioner, FG4)

However, participants commented that it was often unclear to patients where the genetics service fits into their overall care. Patient participants suggested that more efforts could be made by the clinical genetics service to explain the service to patients, and how the service fits in with other medical specialties that may be involved with the patient's care:

In $[\ldots]$ other organisations you have [...] mission statements [...] I don't see it in here where it says this is what the genetic service can do, this is what we're gonna do. This is what [...] (other specialties) are gonna go, this is what your GP's going to do. [...] because if you know that, then you'd actually have a clue $[. .$.$] who you should be querying. (patient, FG6,$ affected with Gorlin syndrome)

\section{Open access and follow-up}

Service users and user representatives highlighted the need for patient follow-up, open access to services and a single point of contact for patients. Patients pointed out that a (further) genetics clinic appointment or a home visit is important, following a genetic test result or a new diagnosis, when enough time has elapsed for the information given to 'sink in'.

It would be nice, if somebody says well, we'll let you sort of get to grips with your results, probably three months, [...] we'll either come and see you, not necessarily in a hospital environment, as you are now, maybe, someone to say we'll come and see you now and go through any issues and concerns, what's uppermost in your mind. (Patient, I10, family history of Huntington disease)

Clinicians acknowledge that because follow-up is at their own discretion, provision is often patchy and patient-driven, and sometimes does not happen because of heavy workload.

I would like to be more proactive in my follow-up, my follow-up is very patient driven, but if my patients telephone I would make an effort to speak to them, but I don't have enough time to remember the person I saw a couple of weeks ago who was quite upset in clinic it would be nice to give them a ring but I'm far too busy dealing with all the new things that are coming through. (Genetic counsellor, FG4) 
From the patients' perspective, having a named person whom they can telephone at any time if they have questions or concerns about the family condition was highly valued.

...I think they've got a good service where you can phone, you phone the (genetic) counsellor, and she's very good. (patient, I3, affected with MEN1)

This would seem to suggest that the reactive approach taken by the genetic counsellor quoted above is important to patients, despite her feeling that she would like to do more. However, it was clear that not all patients feel that they have this named contact and permission to use it.

... access to information from a known person and by that I mean a named person, a point of contact such as a genetics nurse. [...] you could [...] go away with the name and know you can go back to either by letter or phone (User representative, FG5, children have Myotonic dystrophy)

The point was made independently, a number of times, that a yearly contact letter from the clinical genetics department would be highly valued, and serve the purpose of reminding patients that the service is available to them, should any family members wish to avail of it.

...there's no follow up at the moment. You might get a little bit of (genetic) counselling to start with and you don't hear from them at all after that. You need to have this regular support, say a letter, and if you don't want to approach them, if you're fine about it, then that's okay, but if you get this letter saying if there's any problems come back to us, then the family's more likely to go and get this help. (User representative, I11, affected with MEN1)

Interestingly, some participants did have experience of a 'register' service provided by the North West Regional Clinical Genetics service in Manchester for some dominant and $\mathrm{X}$-lined conditions and chromosome translocations that does write to families on a yearly basis, offering further appointments in the genetics clinic. This yearly letter is highly valued by those patients who do receive the register service.

'Well I know one of the things that we found really comforting was that before we even got involved with the baby and things is that we used to get letters each year or every six months from the genetic center $[\ldots]$, and in fact that's what initially made me want to go [.]. So I think that's really important, writing to people, letting them know that even though perhaps you've not needed the services that we've not forgotten about you and we are still here.' (patient, I2, husband carries a balanced translocation)
The service is particularly valued by those patients affected by conditions requiring regular medical examination, such as neurofibromatosis and Gorlin syndrome:

I get a letter every year as part of my Gorlin's syndrome, which means that I have skin cancers and I have jaw cysts and one of the aspects of this is that I have to be regularly examined. So the letter is there as a reminder stroke facilitator if necessary to enable you to be examined (Patient, FG6, Gorlin syndrome)

Although the consensus of opinion in this small sample among those who received yearly register letters from the genetics service was that this was very highly valued, one patient participant affected by adult polycystic kidney disease commented that the yearly letter served as a reminder of his own mortality in relation to his genetic condition. It was commented by some of the user representatives that services are not equitable in this area, because the register service offered by the Manchester centre is not offered elsewhere:

'Another positive is I think is the register system that's operating in Manchester genetics which enables an annual (re)view. [...] I.think the accessibility of it, so once you're into the system, but it's only in Manchester Genetics as far as I know that this actually happens. It doesn't happen with (other) Genetics (centres). You get one bite of the cherry and you're off $[\ldots]$ for most people in the country, it's one stab and then you're on your bike' (User representative, FG2, Neurofibromatosis)

Different questions arise for family members at different life stages, and families value having a long-term relationship with the clinical genetics service that they could draw on at different times in their lives. Many families do not feel the need for regular appointments, but contact with the genetics clinic becomes very important at times such as children reaching reproductive age, and needing counselling about their own risks of transmitting the condition to their children.

'I think sometimes people can sort of put it to the back of their mind until they come to that decision that they might want to have children, and then I think some have sought advice. But I think it's useful for them to know that they can come back at those sorts of times and discuss the issue further.' (User representative, I19, son died from sudden cardiac event)

Part of the importance of follow-up for patients is being updated about research and possible new treatments, and being given the opportunity to participate in new research studies because research is seen as providing hope for the future, if not for themselves, then for their children. 


\section{Coordinated, tailored family care}

Closely related to the finding that patients value open access and yearly follow-up was the finding that patients value a service that provides for the long-term needs of the whole family.

I just feel that it's quite important that it's the extended families as well who I think it should be widened to. (User representative, I18, children affected with Retinitis pigmentosa)

Part of the value of building a relationship with a named person is that this person could then be contacted when children reach an age when they could benefit from some information about the family condition, and their risks of developing or transmitting it. A service oriented towards whole families rather than towards individual patients can facilitate (1) clarifying what the risks are to the wider family (2) family communication about the condition (3) up-to-date information about genetic testing because accuracy of testing can change over time.

... I think parents should have some kind of session to tell them how to deal with their children, and perhaps teenagers should have genetic counselling not the parents, that's what I think just so they know what everything is about, and they can ask questions. (Patient, I6, affected with Marfan syndrome)

The genetics service is seen by patients as having a lot of experience with a broad range of families who may have struggled with issues about how and what to tell their children about the family condition. Patients value guidance from the genetics service about how, when and what to tell their at-risk children about the family condition, so that they can develop effective communication with their children and teenagers about the family condition. Two participants felt that there might be a case, under some circumstances, for the genetics service taking on the responsibility of telling relatives about their risks, if the family were unable to do so.

... if they're able to send information to the people, you know, to the relatives, directly from themselves rather than putting the onus on the family, only I don't know how realistic that is to do... (user representative, I19, son died from sudden cardiac event)

Patients also commented that couples could benefit from having a genetic consultation together, as it can facilitate their communication about the condition, and their feelings about it, which they may not have been able to talk about on their own. The written information provided by the genetics service about the family condition can also facilitate wider communication within the family about the condition, with the confidence that the information is accurate. This is most helpful to families if the information is provided in an accessible jargon-free, lay language. Participants were generally satisfied with service provision in this area, and it was clear that many families have benefited from a family-oriented service. However, the family-oriented nature of the service seems to be an aspect of clinical genetics services that was reported by patients as not well understood by other medical specialties who may consider referral to clinical genetics services appropriate only for couples who are planning to have (more) children.

'...So she asked us if we were having any more children and we said no and that was that then, and the genetic counsellor didn't come up again [...] it's not just about, is it, if we wanted any more children, it's about the bigger picture. [...] So I went to the doctor's and I asked them to refer me myself, nobody asked me, which I thought really was poor, because if I hadn't been the sort of person that had thought to myself, 'Oh well, really I think we should go and see them, even if there is nothing or', you know. I think that everybody in that kind of situation should get the chance to see them. (Patient, son has Fragile $\mathrm{X}$ syndrome)

Following referral to clinical genetics services, this family discovered that the proband's brother, who had had severe learning difficulties all his life, was also affected by Fragile X syndrome, and that she and her mother were both carriers. This was invaluable information to the wider family:

I suppose in a way it was different for me because I found out when (my son) was only young, but my mum as well because obviously (my brother), he's nineteen, and my mum has gone all these years, he's been through special schools and had learning difficulties and that was that, and now she actually knows, you know, she's got a name for it. (Patient, son has Fragile $\mathrm{X}$ syndrome)

\section{Quality of the relationship}

The quality of the relationship between patient and clinician, involving a positive interpersonal interaction, was valued by both patient and health professional participants. A number of aspects emerged as important in contributing to a therapeutic patient-clinician relationship. The first of these was that the clinician should have the social skills and flexibility to relate to people from a variety of socioeconomic backgrounds.

I think the key is with any of these is building up a relationship with the person [...] fortunately I took to (genetic counsellor) [...] we seemed to be on the same wave length, and that makes a difference, but 
she strikes me as the sort that could adapt to any level. You know she could go to the housing estate and come down to that level and go 'You right mate, how are ya?' and I think that is important, because a lot of people don't do that. (patient, I1, son has Duchenne muscular dystrophy)

The ability to listen and empathise with patients was also identified as important.

'I think for me it's more having somebody to talk to and being able to empathise with you, because you know they've spoken to so many different people with many different genetic conditions and obviously they've got a lot of experience in terms of helping you cope and if need be offering you more support. (patient, I2, MEN1)

Related to this was the importance of compassion in the clinician-patient relationship, which participants seemed to equate with empathy and responsiveness.

... it's all about compassion as well, so it's very hard to relate to somebody I suppose when you haven't been through the experience yourself and you're in the medical profession and there's that thing that you have to follow, but it's also about compassion, showing compassion to these parents. (patient group representative, I15, affected with Achondroplasia)

However, it also emerged that a positive interpersonal relationship of this kind was important but not sufficient patients also value being seen by someone who is perceived by them to be an expert in the condition affecting them or their family. Being seen by an expert contributes to the feeling of being understood and appears to be particularly important because of the rarity of genetic conditions and the lack of lay knowledge about them.

... it's just that talking isn't it, but it has to be somebody that knows what it is because otherwise it's just . I mean I've got loads of friends and loads of family but none of them can understand what it's like [...] They're all really good but it's just not the same as talking to somebody who knows about what it is. [...] I've never met anybody, apart from when we go to conferences in Birmingham twice a year with the Fragile X Society, but apart from that I've never met anybody who even knows what it is. (patient, I8, son has Fragile X syndrome).

Patients value services that are provided courteously, and some comments made about clinical genetics services in this area were very complimentary.

... they explain things to you as they're going along instead of keeping you in the dark. [...] I think that is important, treating you like a human being. (patient, I4, affected with Leber's Hereditary Optic Atrophy) You know we were obviously going into the unknown a bit, but, you know, I expect people to be available and I expect people to return calls, and I expect people to follow up in writing, just the person I am [...] and I got exactly that from the hospital and from (the genetic counsellor), so I couldn't have asked for anything more really, I can't really say anything else that we would have wanted so we were quite happy with the service we got. (Patient, I7, carries a Robertsonian translocation)

Some suggestions were made about ways in which services could be provided to be more responsive, such as avoidance of jargon and adequate explanation of medical terms during consultations. Use of jargon by clinicians can be experienced as very threatening for patients most of whom have no medical training. Another suggestion was that clinicians ensure to be adequately prepared for consultations by reading the patient's notes beforehand. Perhaps also related to compassion and responsiveness, patient participants value a service that will have the flexibility to make important telephone calls, such as those communicating prenatal test results, in the evenings, when a couple can be together in the comfort and privacy of their home, rather than alone at their desk at work or on the road in their car.

\section{Time to talk}

Closely related to building good patient-clinician relationships in clinical genetics, seems to be the time available for appointments. This was valued by both patient and health professional participants. Patients do not feel that they are being rushed through and this appears to contribute significantly to their feeling appropriately cared for.

You have a bigger time slot, well we have, when we go to see Professor (Geneticist) for maybe half an hour. And he's familiar with (my daughter) and you know, you just feel like he's interested and he cares. And you just don't get that do you normally. (patient, FG6, NF2)

Patient participants compared clinical genetics services very favourably with other specialties, commenting that in other specialties, they see a different doctor or team of doctors every time who may not have read their notes beforehand, and they feel unable to ask questions. In contrast, in clinical genetics services, patients often see the same clinician every time who knows their history and has more time to spend with them. Because of this, patients do find themselves contacting the genetics service when they have questions about their condition, so that the genetics 
service is almost forced into a coordinating role, as illustrated by this excerpt:

Should you be querying your GP? Or the hospital? Or the genetics service? And without that erm you, it's almost like a scatter gun approach almost. You find the most receptive person to actually go and moan [...] And generally the genetics service comes under that category. Sorry it has to be that way. (patient, Gorlin syndrome)

It's a good job they're there. (patient, Adult polycystic kidney disease)

Yes. It's a good job they're there. (patient, Gorlin syndrome)

FG6

\section{Relationship with outcomes}

The data analysis suggested the hypothesis that all of the process attributes identified in this study can influence patient outcomes. Clearly, the process attributes will not achieve this without effective interventions, but the interventions are more likely to result in improved patient outcomes if the process attributes are in place. In this way, the process attributes and the interventions inextricably link with each other to influence patient outcomes.

\section{Discussion}

This study has identified five distinct process attributes that may contribute to good patient outcomes in clinical genetics services. The identification of 'time to talk' and 'quality of the relationship' as valued attributes in provision of clinical genetics services supports findings in previous studies ${ }^{16-20}$ that relationship dynamics are important for good patient outcomes. There is a long history of process studies in therapeutic counselling and similar debates about the methods used and whether process and outcomes should be studied separately or together. A number of researchers have, however, converged on the importance of the client-counsellor relationship for a successful outcome. ${ }^{29,30}$ This study adds to previous findings in identifying some further specific dimensions of a good quality relationship such as social competence, flexibility and compassion (empathy and responsiveness) on the part of clinicians.

The other three process attributes that were identified here, which relate more to financial and logistical issues, were (1) local and accessible services (2) open access and yearly follow-up and (3) coordinated, tailored family care, have not been identified in previous studies of clinical genetics services as highly valued by patients.

Patient participants in this study valued local and accessible clinical genetics services, describing the challenges faced when more than one family member is affected, and the service is provided at a regional centre which may be very far away. Clinical genetics services in the UK are highly specialised services provided at a regional level according to a 'hub and spoke' model, ${ }^{31}$ involving specialist clinics and some local 'outreach' clinics. However, the clinicians who participated in this research acknowledged that the provision of local 'outreach' clinics is patchy and access to local services is not equitable. This might be one area where it would be of benefit to investigate, using stated preference methods such as a discrete choice experiment, ${ }^{32,33}$ how patients of clinical genetics services might make trade-offs between process and outcome attributes. Stated-preference methods, that use an appropriate design, could also be used to identify which process attributes are most important to patients or service providers. The findings suggest the hypothesis that for families with multiple affected members, access to local services may be particularly important, and patients may be willing to trade this off against other service attributes.

Patient participants in this study emphasised the value of having open access to the clinical genetics service after their first appointment, ideally through a named person who is part of the clinical team, whom the patient can telephone with any concerns. Patient participants wished to develop a long-term relationship with the service, and a yearly letter from the service is highly valued by those patient participants who receive one, and is desired by those who do not receive one. Patients in this study also value a service that provides for the needs of the whole family over the long term. Different combinations of contact and contact type may be possible, and the extent of contact needed to ensure good patient outcomes couldn't be inferred from the findings of this study. This could only be established in larger intervention studies.

These findings could plausibly form part of the model of empowerment. ${ }^{23}$ Empowerment as constructed by McAllister et $a l,^{23}$ describes how clinical genetics services can maximise patient benefits and refers to the empowerment of entire families, not just individual patients. The concept is a 'state' (versus 'trait') including beliefs about one's abilities in the following areas relating to the genetic condition in the family: decision-making, knowledge and understanding, instrumentality (ability to make effective use of the health and social care systems for the benefit of the whole family) and future orientation. ${ }^{23}$ This conceptualisation of empowerment is consistent with recently identified goals of genetic counselling, which include empowering patients. ${ }^{34}$ It is likely that local, accessible services would facilitate appropriate referral. This in turn is likely to facilitate early diagnosis and ensure that families obtain knowledge and information about the family condition, including information about which family members may be at risk for developing or transmitting the condition, thus contributing to empowerment. Open access and follow-up is likely to facilitate the family's ability to make effective use of the health and social care 


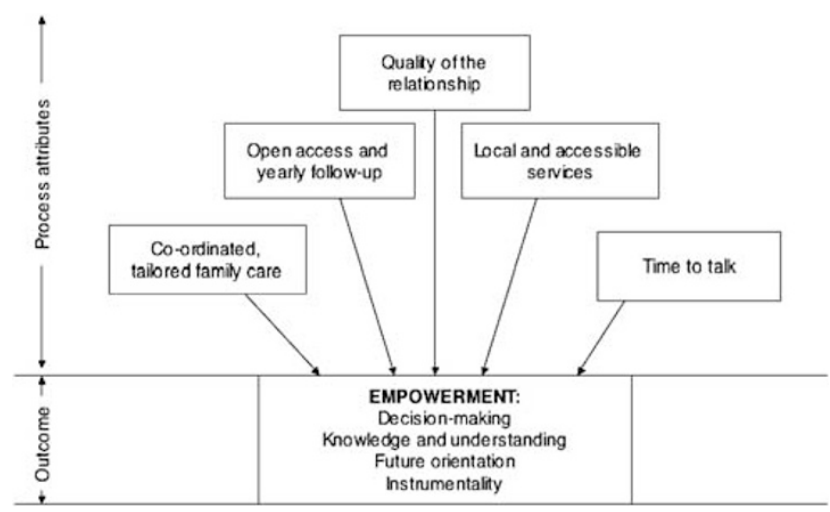

Figure 2 Process attributes that may contribute to empowerment in clinical genetics services.

systems, thus influencing empowerment. Coordinated, tailored family care would ensure that the whole family is empowered, not just the individual patient. Quality of the patient-clinician relationship and time to talk may contribute to empowerment by facilitating adjustment to the genetic condition in the family through responsiveness and effective counselling interventions. Taken together, these process attributes could plausibly influence empowerment by giving families the greatest opportunity to develop the capacity to make informed decisions about their family life, given the genetic condition in the family, to make effective use of the health and social care systems for the benefit of the whole family, and to have hope for the future, if not for themselves then for their descendents (see Figure 2).

In conclusion, this study has identified five process attributes that may be highly valued by patients of clinical genetics services and health professionals involved with provision of those services. These attributes may contribute to good patient outcomes such as empowerment. However, this was a qualitative study and findings cannot be generalised. More research is needed to test the importance of these attributes in influencing patient outcomes from clinical genetics services, and these attributes will be useful in designing models of service delivery that could be tested in intervention studies. Prospective evaluation studies could clarify whether and which process attributes provide demonstrable patient benefits. Future evaluation studies could use outcome measures, recently identified as highly valued by patient and genetics health professionals, ${ }^{24}$ such as decision-making and perceived personal control. Discrete choice experiments could clarify whether and how patients might make trade-offs between process and outcome attributes in clinical genetics services.

\section{Acknowledgements}

We thank the participants who gave their time to contribute to this research. Nowgen is funded by a grant from the Department of Health and the Department of Trade and Industry. Funding is also acknowledged from Central Manchester and Manchester Children's University Hospitals NHS Trust and the Universities of Manchester, Liverpool and Lancaster. The views expressed in this paper are those of the authors and not of the funding bodies.

\section{References}

1 Biesecker BB, Peters K: Process studies in genetic counseling: peering into the black box. Am J Med Genet 2001; 106: 191-198.

2 Birch S, Melnikow J, Kuppermann M: Conservative versus aggressive follow up of mildly abnormal Pap smears: Testing for process utility. Health Econ 2003; 12: 879-884.

3 Stiles WB: Evaluating medical interview process components: null correlations with outcomes may be misleading. Medical Care 1989; 27: $212-220$

4 Silerschatz G: Abuse and disabuse of the drug metaphor in psychotherapy research: hold on to the baby as you throw out the bath. J Consult Clin Psychol 1994; 62: 949-951.

5 Sechrest L: Recipes for psychotherapy. J Consult Clin Psychol 1994; 62: 952-954.

6 Wang C, Gonzalez R, Merajver SD: Assessment of genetic testing and related counseling services: current research and future directions. Soc Sci Med 2004; 58: 1427-1442.

7 Payne K, Nicholls S, McAllister M et al: Towards outcome measures for clinical genetics services: a comparison of genetics healthcare professionals' and patients' views. Health Policy 2007; 84: $112-122$.

8 Harris R: Concerted action on genetic services in Europe: a comparative study of 31 countries. Eur J Hum Genet 1997; 5: $1-220$.

9 Brain K, Norman P, Gray J, Rogers C, Mansel R, Harper P: A randomized trial of specialist genetic assessment: psychological impact on women at different levels of familial breast cancer risk. Br J Cancer 2002; 86: 233-238.

10 Lerman C, Biesecker B, Benkendorf JL et al: Controlled trial of pretest education approaches to enhance informed decision-making for BRCA1 gene testing. I Natl Cancer Inst 1997; 89: 148-157.

11 Wilson BJ, Torrance N, Mollison J et al: Improving the referral process for familial breast cancer genetic counselling: findings of three randomised controlled trials of two interventions. Health Technol Assess 2005; 9: iii-iiv, 1-126.

12 Ryan M: Discrete choice experiments in healthcare. BMJ 2004; 328: 360-361.

13 Michie S, Axworthy D, Weinman J, Marteau T: Genetic counselling: predicting patient outcomes. Psychol Health 1996; 11: 797-809.

14 Stiles WB, Shapiro DA: Disabuse of the drug metaphor: psychotherapy process-outcome correlations. I Consult Clin Psychol 1994; 62: 942-948.

15 Stiles WB: When more of a good thing is better: a reply to Hayes et al (1996). J Consult Clin Psychol 1996; 64: 915-918.

16 Bernhardt BA, Biesecker BB, Mastromarino CL: Goals, benefits and outcomes of genetics counseling: client and genetic counselor assessment. Am J Med Genet 2000; 94: $189-197$.

17 Skirton H: The client's perspective of genetic counseling - a grounded theory study. J Genet Counsel 2001; 10: 311-329.

18 Davey A, Rostant K, Harrop K, Goldblatt J, O'Leary P: Evaluating genetic counseling: client expectations, psychological adjustment and satisfaction with service. J Genet Counsel 2005; 14: 197-205.

19 Duric V, Butow P, Sharpe L et al: Reducing psychological distress in genetic counseling consultations for breast cancer. J Genet Counsel 2003; 12: 243-264.

20 MacLeod R, Craufurd D, Booth K: Patients' perceptions of what makes genetic counseling effective: an interpretive phenomenological analysis. J Health Psychol 2003; 7: 145-156. 
21 McAllister M, Payne K, Nicholls S, MacLeod R, Donnai D, Davies $\mathrm{L}$ : Improving service evaluation in clinical genetics: identifying effects of genetic diseases on individuals and families. J Genet Counsel 2007; 16: 71-83.

22 McAllister M, Payne K, Nicholls S, MacLeod R, Donnai D, Davies L: The emotional effects of genetic disease: implications for clinical genetics. Am J Med Genet 2007; 143A: 2651-2661.

23 McAllister M, Payne K, Nicholls S, MacLeod R, Donnai D, Davies L: Patient empowerment in clinical genetics services. I Health Psychol 2007 (in press).

24 Payne K, Nicholls S, McAllister M, MacLeod R, Donnai D, Davies L: Outcome measurement in clinical genetics services: a systematic review of validated measures. Value in Health 2007; 11: 497-508.

25 Miles MB, Huberman AM: Qualitative data analysis: An expanded sourcebook. London: Sage, 1994.

26 Glaser BG, Strauss AL: The discovery of grounded theory. London: Weidenfeld \& Nicholson, 1967.

27 Strauss A, Corbin J: Basic of qualitative research: Techniques and procedures for developing grounded theory, 2nd edn London: Sage, 1998.
28 McAllister M: Grounded theory in genetic counseling research J Genet Counsel 2001; 10: 233-250.

29 Lambert MJ: Implications of outcome research for psychotherapy integration; in Norcross JC, Goldfried MR: Handbook of Psychotherapy Integration. New York: Basic Books, 1992, pp 94-129.

30 Elliott R, Fox CM, Beltyukova SA, Stone GE, Gunderson J, Zhang $\mathrm{X}$ : Deconstructing therapy outcome measurement with Rasch analysis: the SCL-90-R. Psychol Assess 2006; 18: 359-372.

31 Donnai D, Elles R: Integrated regional genetics services: current and future provision. BMJ 2001; 322: 1048-1052.

32 Hall J, Fiebig DG, King MT, Hossain I, Louviere JJ: What influences participation in genetic carrier testing? Results from a discrete choice experiment. J Health Econ 2006; 25: 520-537.

33 Ryan M, Gerard K: Using discrete choice experiments to value health care programmes: current practice and future challenges. Applied Health Econ Health Policy 2003; 2: 1-10.

34 McCarthy Veach P, Bartels DM, LeRoy BS: Coming full circle: a reciprocal-engagement model of genetic counseling practice. J Genet Counsel 2007; 16: 713-728. 